Kastamonu Eğitim Dergisi
$\begin{aligned} & \text { Kastamonu Education Journal } \\ & \text { Ocak 2020 Cilt:28 Sayı:1 } \\ & \text { kefdergi.kastamonu.edu.tr }\end{aligned}$

\title{
80’lerden Günümüze Yükseköğretimde Kalite Çalışmaları: Küresel Ölçekte Bilimetrik Bakış
}

\section{Quality Studies in Higher Education from 1980s to Present: Scientometrics Overview on a Global Scale}

\author{
Güzin ÖZDAĞoĞLU ${ }^{1}$, Muhammet DAMAR², Aşkın ÖZDAĞOĞLU³ ${ }^{3}$ Hale TURHAN DAMAR ${ }^{4}$ Özlem Bílik ${ }^{5}$
}

Öz

Yükseköğretim kurumları, eğitim-öğretim, araştırma-geliştirme gibi faaliyetleriyle, topluma farklı katmanlarda değer ve hizmet üreterek, toplumun gelişmişlik düzeyine olumlu katkılar sağlamaktadır. Toplumların, geleceklerine, yükseköğretim kurumlarının yön vereceğine olan inançları artarken, bu durum, kurumlardan beklenen eğitim ve hizmet kalitesi düzeyini de aynı doğrultuda artırmaktadır. Dolayısıyla, yükseköğretimde kalite konusu, farklı kalite model ve standartların geliştirilmesiyle, araştırma için ilham kaynağı olarak göz önüne alınmıştır. İlgili literatürün mevcut yapısını ortaya koymak amacıyla, bu araştırmada, "yükseköğretimde kalite" konusundaki araştırma makaleleri bilimetrik yöntemler ile incelenerek, ilgili alandaki eğilimler küresel ölçekte sunulmuştur. Çalışmada; Web of Science (WoS) veri tabanında bulunan, 1980-2018 tarih aralığında yayınlanmış, başlığı yükseköğretimde kalite kavramı ile ilişkilendirilmiş araştırma makaleleri analiz edilmiştir. Bilimetrik yöntem ve araçların desteğiyle, kapsama alınan makalelerin en fazla referans verdikleri dergiler, en fazla referans verilen yazarlar ve en fazla yayın üreten ülkeler, özet tablolarla; yazarların ve anahtar kelimelerin kendi arasındaki ilişkiler ise kümeler ve ağ yapısı içerisinde sunulmaktadır.

Anahtar Kelimeler: yükseköğretim, kalite, üniversite, bilimetri.

\section{Abstract}

Higher education institutions contribute positively in the development level of the society by producing values and services in different layers via the activities such as higher education programs and research and development projects. The social beliefs in higher education institutions in leading and shaping the future of society have risen with an increasing trend, therefore, the expectations from the institutions also have increased in the same direction. The expectations have been considered as the sources of inspiration for the research on quality in higher education figuring out the developments and the use of various models and standards. In order to reveal the current characteristics of the relevant literature, this research aims at examining the research articles on "quality in higher education" with the help of scientometrics, and thus presenting the related trends are presented on a global scale. In this study, the research articles in Web of Science were considered in the analyses the titles of which include "higher education" and "quality", and related issues that were published between 1980 and 2018. With the support of techniques and tools of scientometrics, the most cited journals, the most cited authors and the most publishing countries were summarized in tables; the relations among the authors and among the keywords are presented in a network structure

Keywords: Higher Education; Quality, University, Scientometrics.

\footnotetext{
${ }^{1}$ Dokuz Eylül Üniversitesi İşletme Fakültesi İşletme Bölümü İzmir-Türkiye, guzin.kavrukkoca@deu.edu.tr, https://orcid.org/0000-0003-3055-3055

${ }^{2}$ Dokuz Eylül Üniversitesi Bilgi İşlem Daire Başkanlığı İzmir-Türkiye, muhammet.damar@deu.edu.tr, https://orcid.org/0000-0002-3985-3073

${ }^{3}$ Dokuz Eylül Üniversitesi İşletme Fakültesi İşletme Bölümü İzmir-Türkiye, askin.ozdagoglu@deu.edu.tr, https://orcid.org/0000-0001-5299-0622

${ }^{4}$ İzmir Demokrasi Üniversitesi Sağlık Hizmetleri Meslek Yüksekokulu Yaşlı Bakımı Programı İzmir-Türkiye, hale.turhan1986@gmail.com, https://orcid.org/00000002-1218-5319

${ }^{5}$ Dokuz Eylül Üniversitesi, Hemşirelik Fakültesi, Cerrahi Hemşireliği Bölümü, İzmir-Türkiye, ozlem.bilik@deu.edu.tr, https://orcid.org/0000-0002-8372-8974 Atıf / Citation: Özdağoğlu, G., Damar, M.,Özdağoğlu, A., Turhan Damar H. ve Bilik, Ö. (2020). 80'lerden Günümüze Yükseköğretimde Kalite Çalışmaları: Küresel Ölçekte Bilimetrik Bakış. Kastamonu Education Journal, 28(1), 482-493. doi:10.24106/kefdergi.3684
} 


\section{Extended Abstract}

Introduction: Higher education institutions contribute positively in the development level of the society by producing values and services in different layers via the activities such as higher education programs, and research and development projects. The social beliefs in higher education institutions in leading and shaping the future of society have risen with an increasing trend, therefore, the expectations from the institutions also have increased in the same direction. The expectations have been considered as the sources of inspiration for the research on quality in higher education figuring out the developments and the use of various models and standards.

Aim: In order to reveal the current characteristics of the relevant literature, this research aims at examining the research articles on "quality in higher education" with the help of scientometrics, and thus presenting the related trends are presented on a global scale. In this study, the research articles in Web of Science were considered in the analyses the titles of which include "higher education" and "quality", and related issues that were published between 1980 and 2018.

Method: The dataset, collected between 26.07.2018 and 27.07.2018 included 1949 articles and then the articles were evaluated regarding the relevance of the paper with the selected topic. Finally 570 articles were discarded from the dataset and 1379 articles were examined which cover 3604 writers, 1434 universities and 95 countries. With the support of techniques and tools of scientometrics, the most cited journals, the most cited authors and the most publishing countries were summarized in tables; the relations among the authors and among the keywords are presented in a network structure. In the process of creating tables and images and calculating metrics, particular software packages were used such as electronic spreadsheets (MS-Excel) and VOSViewer (van Eck and Waltman, 2009) Besides, a novel computer program was developed to be able to preprocess and customize the data with SQL queries to obtain various findings.

Results and Discussion: When the first statistics are analyzed, there is an increase in the number of research articles on quality studies in higher education. The $\mathrm{H}$-index value calculated as an indicator of citation performance is 52 , the average citation rate or the corrected quality ratio is 9.79 , and the total number of citations performed at all times is 13499 . When compared to general trends, these values indicate that the subject is an intensive study area. The Collaboration Index of the publications in the data set was found to be 2.61. According to this value, it can be said that there are three researchers on average in the production of these articles. The Publication Frequency calculated with similar inputs is 0.38 and shows the number of articles per author in this field. When these two indices are evaluated, it can be concluded that common studies are predominant in this field.

It is seen that the related researches do not only have studies regarding quality system in universities, faculties and vocational schools but also the issues that affect the quality of higher education such as the development of libraries and standards (Coleman and Jarred, 1994; Ifidon, 1995), laboratory accreditation (Bode, 1995) and improvement programs (Nielsen, 1997), internship subjects (Sarwerfoner, 1981), university website quality (Thelwall, 2002), quality of life students and job satisfaction of both and employees (Tolor, 1983; Daskapan, Tuzun and Eker, 2005; Damush, Hays and DiMatteo, 1997), and the effect of facilities on education (Mateo, Fernandez, 1996). Besides, the quality of the services offered at the university (Johnsrud, 2002) and universitycommunity cooperation (Bass, 1987) are among the other topics discussed in the literature. The keyword networks and top articles given in this study can be examined for details.

It was observed from the co-occurrence of keywords network (with time dimension) that studies on total quality in higher education have increased significantly after 90's (Hansen, 1993; Cowles and Gilbreath, 1993; Coate, 1993). The concept has been studied in the literature of education over the years, in a broad range from a total quality management to a kaizen approach (Clayton, 1995). Total quality management was first handled by Çoruh (1996) in Turkey just one year later. In the 2000s, the concept of higher education and quality has become an important topic discussed in the literature which has no boundaries due to the impact of globalization (Farrington, 2001). This situation can be considered as an indicator of internationalizationglobalization and quality requirements (Van Damme, 2001) and also a triggering factor (Yonezawa, 2002; Vidovich, 2002) in global market. The intensity of the research regarding distance education and quality has increased after 2004-2005 (Clarke, Butler, Schmidt mid Hansen and Somerville, 2004). In 2010 and beyond, problem-based learning (Rakhudu, 2015); university industry cooperation (Kauppila, Mursula, Harkonen and Kujala, 2015); quality in private and public universities is also discussed as important topics (McCowan, 2004). In addition to these, the concept of equality in the context of quality in higher education is also one of the topics covered in the related literature (Schwartzman, 2004).

Conclusion: In the framework of the results obtained from the author and journal statistics, the researchers in this field should follow the journals, in particular, Higher Education (f: 60, 4.35\%), Quality In Higher Education (f: 32, 2.32\%), Total Quality Management ( $f: 26,1,88 \%$ ) by considering the number of publications they provided on the subject. In addition, the researchers who have made significant contributions to the field (Gelaye B, Hou AYC, Williams MA, Unsal A, Lowe D, Rogers SN, Sarrico CS) can be recommended to the researcher to read and follow.

Turkey in the relevant field comes after Canada in the seventh place with 40 studies and 371 citations. These statistics are not adequate for Turkey where there exist many higher education institutions and researchers, In order to encourage research in this area, it may be advisable to create project calls and to support more congress symposiums and conferences related to quality in higher education. 


\section{Giriş}

Eğitim ve öğretim, bireysel/toplumsal, sosyal, siyasal, hukuksal ve ekonomik olarak ilerlemenin ve gelişimin, ayrıca yüksek yaşam seviyesi elde edebilmenin başlıca yolu ve temeli olarak görülmektedir. Günümüzde, bilgi toplumuna giden yolda ve bilgi toplumunun üst seviyelerine tırmanma sürecinde, en önemli görevi üstlenen kurumlar yükseköğretim kurumlarıdır. Çünkü bu kurumlar, bilgi ekonomisinin hammaddesi olan bilginin üretiminden ve dağıtımından sorumlu temel yapılardır (Tonta, 1999). Yükseköğretim, sadece günümüzde değil, tarihsel sürecin her çağında ağırlığını ve varlığını hissettirmiş ve bu açıdan kendisini geliştiren toplumlara her zaman üstünlük kazandırmıştır.

Yükseköğretimin geçmişi, Çin Hanedanlığının kurduğu okullardan, İskenderiye'deki müze ve kütüphanelere, 1000'lerde Bağdat'ta Büyük Selçuklu Devleti'nde kurulan Nizamiye Medresesi'ne kadar uzanmakta olup, Anadolu topraklarındaki Türk uygarlıkları için ilk örnekler, 1200 'lerde Kayseri'de Çifte Medrese, Konya'da Karatay Medresesi, Erzurum'da Çifte Minareli Medrese olarak gösterilmektedir. Bunun yanında, çağdaş üniversitelerin temellerinin ise, 1000 ve 1100 'lerde Avrupa'da kurulan Bologna, Paris ve Oxford Üniversiteleriyle atıldığı düşünülmektedir (Doğramacı, 2007). Günay ve Günay (2017)’ın, Türkiye'de yükseköğretimin tarihi gelişimi ve mevcut durumunu ortaya koyan araştırmaları, bu kapsamda yapılan güncel çalışmalara örnek olarak verilebilir.

Yükseköğretim kurumlarının birincil amacının belirli alanlarda yetkin bireyler yetiştirmek olduğu düşünülürse, bu kurumların toplumların geleceği için önemli bir rol üstlendiği açıktır. Bu açıdan yükseköğretim kurumlarının, eğitim-öğretim, araştırmageliştirme ve topluma hizmet gibi tanımlanmış ve kritik önem taşıyan görevleri ve faaliyetleri bulunmaktadır. Bu faaliyetlerin gerçekleştirilmesinde kaliteyi hedef alan bir yönetim anlayışının benimsenmesi, sunulan hizmetlerin verimi üzerinde önemli rol oynamaktadır (Gencel, 2001).

Yükseköğretim için kalite tanımı beş farklı yaklaşım ile yapılmaktadır: istisnai nitelik olarak kalite; mükemmellik ya da tutarlılık olarak kalite; amaca uygunluk olarak kalite; ekonomik değer olarak kalite ve dönüşüm olarak kalite (Harvey ve Green, 1993). Yükseköğretim kurumlarında, bu beş farklı açıdan tanımlanan kalite, öğrencilerin, bilim insanlarının, toplumun ve iş dünyasının beklentilerine uygun hizmetler üretebilmek adına, her geçen gün üzerine daha da çok anlam yüklenen, belirli standartlara ve yönetim sistemlerine bağlanan bir kavram olmaktadır. Bu yoğun çaba kurumların, öğrencileri akademik yaşama ve iş yaşamına hazırlayabilme, araştırma-geliştirme faaliyetlerine uygun alt yapı olanakları sunabilme ve insana yatırım yaparak, toplumun gelişmişlik düzeyine katkı sağlayacak diğer faaliyetleri gerçekleştirebilme kaygısının bir sonucu olarak ifade edilebilir.

1975’lerden itibaren küresel ölçekte gelişen ülkeler, bilgi toplumuna geçiş sürecine başlamışlar ve bilginin merkezde olduğu bir ekonomik yapı oluşturmaya başlamışlardır. Bu yapılanma ile bireyin ekonomik gücü, bilgi ve öğrenim düzeyleriyle, ülkelerin rekabet gücü ise beşeri ve sosyal sermayeleri ile ölçülebilir duruma gelmiştir. Bu süreç, bilginin üretimi ve paylaşımından birinci derecede sorumlu olan yükseköğretim kurumlarından beklenti düzeyini arttırmış ve yükseköğretim, tüm toplumlarda ilgi odağı haline gelerek yeniden yapılanma sürecine girmiştir (YÖK, 2007). Bu açıdan, geleneksel yaklaşımlar bırakılmakta, göstergelere dayalı ölçme ve değerlendirme yapılmasına, ulusal ve uluslararası seviyede bağımsız organların ve uluslararası seviyede kalite standartlarının oluşturulmasına yönelik çalışmalar zaman içinde hep gündemde kalmaktadır (Tezsürücü ve Bursalıoğlu, 2013). Örneğin, Avrupa'da, ortak bir Avrupa Yükseköğretim Alanı ve Avrupa Araştırma Alanı oluşturma çalışmaları Bologna Süreci ile şekillenmiştir. Sonraki süreçlerde ise bu yapı desteklenerek geliştirilmiştir. Bu bağlamda, Avrupa Yükseköğretimini güçlendirme, kalite düzeylerinin yükseltilmesi ve ortak kabul gören belli standartlarda yükseköğretim sistemlerinde kalite güvence sistemlerinin oluşturulması gibi çalışmalar, yükseköğretim politikalarında ön sıralarda yer almıştır (Gür ve Özer, 2012).

Küresel ekonomideki rekabet ve yarış ile birlikte, bilginin merkezde olduğu ve bilginin işlenip anlamlandırma çabasıyla ortaya çıkan bilişim teknolojilerindeki gelişmeler, ülkelerin her alanda olduğu gibi yükseköğretim alanında da sistemlerini değerlendirmelerini ve yeni bir yapılanmaya girmelerini zorunlu kılmıştır (YÖDEK, 2007). Bu gelişmeler, ülkemizde yükseköğretim alanında yapılan kalite iyileştirme ve sistem geliştirme çalışmalarını da yakından etkilemiş olup, kısmi olarak geliştirilen ve uygulanan sistem ve yaklaşımlardan, ulusal bağlamda merkezi olarak benimsenen yükseköğretim alanına doğru önemli adımlar atılarak, bu süreç, karşılaşılan bir fırsatlar zinciri haline getirilmeye çalışılmıştır (Belenli vd., 2011).

Yükseköğretimde kalite bağlamında yaşanan tüm bu iyileşmeler, doğal olarak bu alanda yeni yaklaşımlar geliştiren, farklı katmanlarda ve platformlarda bu doğrultuda projeler üreten bilim insanlarının başarısı olarak tanımlanabilir. Bu çalışmaların birikimiyle, geçmişten bu yana yükseköğretimde kalite güvence ve iyileştirme çalışmaları ile ilgili literatür zenginleşmekte, pek çok kurum için önemli bir deneyim paylaşımı ve bilimsel altyapı geliştirme ortamı sağlamaktadır.

Bu çalışmada, 80'li yıllardan günümüze uzanan tarihsel süreçte, yükseköğretimde kalite konusunda yapılan çalışmaların bilimetrik karakteristikleri ortaya konmaktadır. Çalışmanın temel amacı, yükseköğretim ve kalite alanında makro boyutta yapılmış ve yayınlanmış araştırma makalelerini farklı demografik boyutlar ışığında bilimetrik yöntemler ile inceleyerek, bu alandaki eğilimleri küresel ölçekte ortaya çıkarmak ve bu ölçek içinde Türkiye'nin yerini tartışmaktır. Çalışma kapsamında, yükseköğretim ve kalite alanında gerçekleştirilen araştırmalar, dergi, ülke, üniversite, konu başlıkları, alandaki önemli yazarlar ve önemli eserler kapsamında analitik bir bakış açısıyla özetlenmektedir ve bu alanda çalışan veya çalışacak araştırmacılara bir perspektif sunacağı düşünülmektedir.

Çalışmanın hedeflenen çıktılarına ulaşmak için bilimetri yönteminden yararlanılmıştır. Bilimetri bibliyometri, infometri gibi yöntemler, literatürdeki belirli bir konunun kalıplarını, bağlantılarını ve demografik özelliklerini ortaya çıkarmaya odaklanan benzer araştırma yöntemleridir. Geçmişteki teoriler ve kullandıkları araç ve teknikler ortak olmakla birlikte, analizler içinde odaklandıkları 
konular ve boyutlarda farklılıklar bulunmaktadır (Yang ve Yuan, 2017). Bilimetri çalışmalarında, yazarların, anahtar kelimelerin ve atıfların farklı metriklerle hem özet istatistikleri verilmekte hem de ortaklık, zaman ve kümelenme bağlamında ileri veri analizlerinin sonuçları ağ ve yoğunluk görselleriyle sunulabilmektedir. Bu noktada metin analitiği ve ağ modellerinden yararlanılır (Hosseini vd., 2018). Bu kapsamdaki çalışmalarda sıklıkla, Web of Science, Scopus ve PubMed gibi bilimsel veri tabanları tarafından sağlanan bibliyometrik veriler kullanır. Garfield (2009) bilimetrik yöntemin tarihsel gelişimini kronolojik yapıda detaylı olarak ele almıştır.

Çalışmanın akışında, öncelikle, yükseköğretimde kalite çalışmalarının tarihsel seyri, geniş bir literatür incelemesiyle özetlenmekte; izleyen bölümde ise yöntem kapsamında, veri kaynağı ve özellikleri ile yapılan bilimetrik analizlerin ve geliştirilen görsellerin detayları açıklanmaktadır. Yöntem bölümünde açıklanan analiz türlerinin uygulamasıyla birlikte temel çıktılarının da yer aldığı bulgular bölümünü ise bu bulguların birlikte değerlendirildiği tartışma ve sonuç bölümüyle çalışma sonlandırılmaktadır.

\section{Literatür İncelemesi}

Literatürde yer alan çalışmalar incelendiğinde, yükseköğretimde kalite güvence ve kalite kavramının pek çok ülkede üzerinde önemle durulan bir konu olduğu görülmektedir. Bu konuda yoğun çalışma yapan ülkelerden biri Romanya'dır. Bologna süreci ile uyumlu olarak Romanya'daki teknik okulların değerlendirilmesi (Todorescu, Greculescu ve Lampă, 2014); Romanya'daki üniversitelerin değerlendirilmesi (Gorea ve Saharov, 2015); Avrupa'da yükseköğretimde kalite güvencesi için uygulamaya konulan standartların etkisini ölçmek amacıyla standartların öncesi ile sonrasındaki durumun Romanya'da yükseköğretim açısından karşılaştırılması (Prisacariu, 2015); Romanya'da mühendislik öğrencilerine yönelik olarak kalite güvence ve sınıf yönetimi açısından Ingilizce derslerinin değerlendirilmesi (Popescu-Mitroi, Todorescu ve Greculescu, 2015) gibi çeşitli çalışmaların yapıldığı görülmektedir. Yükseköğretimde kalite güvence için farklı ülkelerde yapılan çalışmalara örnek vermek gerekirse, Etopya'da hem özel üniversitelerin hem de devlet üniversitelerinin kalite güvence açısından incelenmesi (Adamu ve Addamu, 2012); genel olarak Bologna kapsamına giren Avrupa ülkelerinde kalite güvence kavramı (Keçetep ve Özkan, 2014); İngiltere ve ABD’de yükseköğrenim kalitesinin tartışılması (Moodie, 1988); Avustralya üniversitelerinde araştırma kalitesi (Brown ve Nunn, 1981); Malezya'da toplam kalite yönetimi ve yükseköğretim (Kanji ve Tambi, 1998); Afrika üniversitelerinde kaliteli eğitim (Burgess, 1989); İsveç yükseköğretiminde kalite ve verimlilik (Tuijnman, 1990); Kuzey Kıbrıs Türk Cumhuriyeti'nde kalite güvencenin değerlendirilmesi (Sarı, Fırat ve Karaduman, 2016) ve Güney Kore'de yükseköğretimi geliştirmede bir politika aracı olarak kalite güvencesinin incelenmesi ifade edilebilir (Shin, 2017).

Yükseköğretim alanında gerçekleştirilen bilimetrik ve bibliyometrik çalışmalar küresel ölçekte değerlendirildiğinde, İngiliz yükseköğretim kurumlarında araştırma kalitesini ölçmek için bibliyometri kullanımı (Adams, 2009); “E-universcience" kavramı içinde yer alan üniversite topluluğunun üyelerinin araştırmalarının santigratmetrik kantifikasyon hizmetlerinin kalite yönetimi (Bogdan, Iuliana, Valentin, ve Vasile, 2009) ve anahtar kelimelerin eş oluşumlarını analizini kullanarak yükseköğretimdeki kalitenin literatür yapısını haritalama amaçlı kullanımı (Alzafari, 2017) gibi çalışmalarla karşılaşılmaktadır. Küresel ölçekteki yükseköğretimde kalite çalışmaları ile Türkiye adresli çalışmaları kıyaslayan ve bunu tartışan bir çalışmayla literatürde karşılaşılmamıştır.

Yükseköğretimde kalite kapsamında, kalite güvence odak noktası dışında da çeşitli kavramların yer aldığı görülmektedir. Kalite yönetimi, kalite kültürü, toplam kalite yönetimi, altı sigma, iş süreçleri modelleme konuları da yükseköğretim kalitesinin geliştirilmesine yönelik literatürde sık sık karşılaşılan kavramlardır. Örneğin iş süreçleri modellemeye dayalı bir kalite yönetimi için değerlendirme yapılması (Dragan, Ivana ve Arba, 2014), Dicle Üniversitesi Diyarbakır Meslek Yüksek Okulu'nda toplam kalite yönetimi uygulamalarını incelemek amacıyla öğrencilere anket yapılması (Karahan ve Mete, 2014), yüksek öğretim kurumlarını geliştirmek için altı sigmanın kalite yönetim sisteminde kullanımı (Adina-Petruta ve Roxana, 2014), yüksek öğretimde kalite kültürünün gelişimi (Barbulescu, 2015), yüksek öğretimde kalite yönetimi (Draguta, 2011), Türkiye'deki 241 fakülte ve enstitünün incelenerek kalite yönetimi açısından değerlendirilmesi (Eryılmaz, Kara, Aydoğan, Bektaş ve Erdur, 2016), Brezilya'da yükseköğretim kalitesini iyileştirmek amacına yönelik olarak yükseköğretim değerlendirme modelinin kavram haritası yardımıyla oluşturulması (Pereira, Araujo, ve Machado-Taylor, 2018), kurum yapısı, sorumluluklar, kurumsal kaynaklar ve yönergeleri dikkate alan bir yüksek öğretimde kalite sistemi uygulaması (Rezeanu, 2011), akademik kurumların kalitesini iyileştirmek adına toplam kalite yönetimi ilkelerinin göz önüne alınması gerekliliği (Todorut, 2013) belirtilebilir. Akademik yayın performansı da yükseköğretimde bir performans göstergesi olarak alındığında, Özdemir ve Alpaydın (2018) tarafından gerçekleştirilen ve Dergipark üzerinde yer alan üniversite dergilerinin akademik yayıncılık kapsamında analiz edildiği araştırma, bu kapsamdaki çalışmalara örnek olarak verilebilir.

\section{Yöntem}

Önceki bölümlerde ifade edildiği gibi, bu çalışma, yükseköğretimde kalite alanında yayınlanmış araştırma makalelerini farklı demografik boyutlar ışığında bilimetrik yöntemler ile inceleyerek, bu alandaki eğilimleri küresel ölçekte ortaya çıkarmayı hedeflemektedir. Planlanan analizler, aşağıdaki bulgulara ulaşmayı amaçlamaktadır:

Yükseköğretimde kalite konusunda yapılan yıllar boyunca izlediği eğilim ve literatürdeki konumu,

Yükseköğretimde kalite konusunda oluşan literatürde kurumlar ön plana çıkan yazar, kurum ve dergiler,

Anahtar kelimelerin ve ele alınan konuların oluşturduğu kümler ve bunların zamana göre dağılımı. 
Amaçlanan bilgilere ulaşmak için pekçok istatistik tablo ve grafiğin kullanılmasının yanı sıra, metin madenciliği ve ağ analiz yöntemlerinin de yardımıyla ileri analizler ve görselleştirme yapılabilmiştir. Ayrıca literatürün geldiği konumu açıklayabilmek için geliştirilen metriklerden de yararlanılmıştır.

\section{Veri Kaynağı ve Özellikleri}

Çalışmada, Web of Science veri tabanında bulunan ve SCI-EXPANDED, SSCl, A\&HCl, CPCI-S, CPCl-SSH, ESCI indekslerince taranan, 1980-2018 tarih aralığında yayınlanmış, 1379 araştırma makalesi, 3604 yazar, 1434 üniversite, 95 ülke bilimetrik yöntemler ile analiz edilmiştir. Veriler 26.07.2018-27.07.2018 tarihleri arasında toplanmıştır. 1980-2018 yılları arasında araştırma olarak yayınlanan, başlığında "quality" ve "higher education" kelimeleri geçen 1949 makale uzman görüş sonrası filtrelenerek 1379 çalışmaya ulaşılmış ve analiz kapsamına alınmıştır.

Elde edilen ilk veri listesi üzerinde yapılan ek filtreleme sürecinde, yükseköğretimde kalite akreditasyon çalışmaları; üniversite hastanelerinde, üniversite laboratuvarlarında, kütüphanelerde ve üniversitenin organik parçası olan diğer birimlerde, eğitim kalitesi ile ilişkili bulunan makaleler analizlere dahil edilmiştir. Üniversite öğrencilerinin veri kaynağı olarak seçildiği çalışmalar, eğer yükseköğretimde kalite ile ilişkisi yok ise veri setine alınmamıştır.

Yükseköğretim alanında öğretim planı geliştirme, ölçme-değerlendirme gibi alt başlıklarda yapılmış kalite iyileştirme çalışmaları bulunmaktadır. Ancak, bu çalışmanın kapsamında, yükseköğretimde kalite kavramına yön veren makaleler incelenmiştir. Başlık bazında yapılan makale araştırmasının amacı da bu doğrultudaki çalışmalara ulaşabilmektir.

\section{Kullanılan Teknikler ve Araçlar}

Veri tabanından elde edilen Web of Science (Clarivates Analtyics) raporları ve sorguları, seçilen alandaki demografik özellikleri incelemek için kullanımıştır. İleri veri analizleri kapsamında, alanın bilimsel perspektiflerini ortaya koymak amacıyla, alıntılar, ortak alıntılar, ortak yazarlar, ortak kelimeler, demografik karakteristikler ve bu kapsamda dergiler, ülkeler kurumlar arasındaki bağlantılar, kümeleme analizleri ve ağ modelleri ile elde edilerek, görsel olarak sunulmuştur.

İlgili literatürün küresel ölçekteki yerini ve performansını sunabilmek için kullanılan ve aşağıda tanımlanan endekslerden yararlanılmıştır.

- Hirsch tarafından ortaya atılan h-endeksi bilim insanlarının ve bilim alanlarının performansını ölçmek amacıyla kullanılan ve tüm yayınların kaçının belli bir değer üzerinde atıf aldığını göstermektedir (Al, 2008, s. 265).

- Iş̧birliği Endeksi, belirli bir alanda ortak çalışma düzeyini ifade etmekte olup, Denklem 1 ile hesaplanmaktadır (Ergul, Ardahan, Temel ve Yıldırım, 2010, s. 51; Pardo, Reolid, Delicado, Mallebrera ve Garcia-Meseguer, 2001, s. 935-936; Vinkler, 2010, s. 207).

$$
C I=\frac{K}{P}
$$

(Cl:işbirliği endeksi, P:makale sayısı, K:araştırmacı sayısı)

- Düzeltilmiş Kalite Oranı (Vinkler, 2010), belirli bir konudaki yayınların atıf durumunu göstermektedir (Denklem 2).

$$
\begin{aligned}
& C Q=\frac{C}{P} \\
& \text { C:atıf sayısı,CQ:düzeltilmiş kalite oranı. }
\end{aligned}
$$

- Belli bir konuda çalışan yazarların ürettiği makale sayısını ifade eden Yayın Frekansı (Vinkler, 2010, s. 207) ise Denklem 3 aracılığıyla hesaplanmaktadır.

$$
\begin{aligned}
& P F=\frac{P}{K} \\
& \text { (PF:yayın frekansı) }
\end{aligned}
$$

- Atıf Alma Durumu metriği (Vinkler, 2010, s. 234), ülke bazında ortalama atıf sayısını göstermekte olup, Denklem 4 aracılığıyla hesaplanmaktadır.

$$
J P C=\frac{C_{t}}{P_{t}}
$$

(JPC:Ülke bazında atıf alma durumu, C_t:ülkenin aldığı atıf sayısı, P_t:ülkenin yaptığı yayın sayısı)

Tabloların ve görsellerin oluşturulması ve metriklerin hesaplanması sürecinde, elektronik hesap tablolarına (MS-Excel), VOSViewer (van Eck ve Waltman, 2009) gibi paket programlara ek olarak, Web of Science verilerini daha detaylı işleyebilmek için Oracle veri tabanıyla bütünleşik çalışan ve PHP programlama diliyle yazılmış özgün bir program kullanılmıştır. Geliştirilen ek program SQL sorgularıyla, özel analizler için veri setinde özelleştirme ve önişlemeler yapılabilmiştir. Bu araştırma soruları ışığında, izleyen kısımda bulunan sonuçlar aktarılmaktadır.

\section{Bulgular}

Bilimetrik analizlerin yapılabildiği yazılım platformlarında, farklı boyutlarda ilgili literatürün genel seyrini özetlemek mümkün olabilmektedir. Bu kapsamda sunulan Şekil 1, yıllara göre makalelerin sayısal değişimini ve toplam atıf sayısı gibi bazı metrikleri göstermektedir. Yıllara göre yükseköğretimde kalite çalışmalarına yönelik araştırma makalelerinin sayısında artış görülmektedir. Atıf performansının göstergesi olarak hesaplanan $\mathrm{H}$-endeksi değeri 52, ortalama atıf oranı ya da düzeltilmiş kalite oranı ise 9,79 
olup, tüm zamanlarda gerçekleştirilen toplam atıf sayısı 13499'dir. Genel eğilimlere göre bu değerler, konunun yoğun bir çalışma alanı olduğuna işaret etmektedir. Ele alınan veri setindeki yayınların İşbirliği Endeksi 2,61 olarak bulunmuştur. Bu değere göre, makalelerin üretiminde ortalama olarak üç araştırmacının yer aldığı söylenebilir. Benzer girdilerle hesaplanan Yayın Frekansı ise 0,38 olup, bu alanda yayın yapan yazar başına düşen makale sayısını göstermektedir. Bu iki endeks değerlendirildiğinde, alanda genelde ortak çalışmaların ağırlıklı olduğu sonucuna varılabilmektedir.

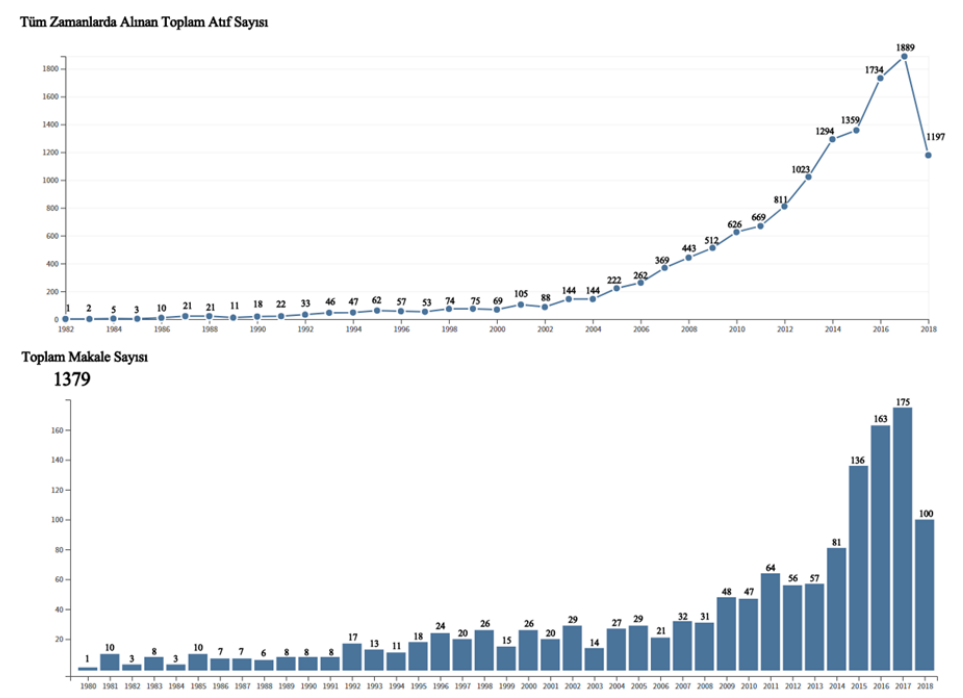

\section{Şekil 1. Yıllara göre makale ve makalelerin atıf sayılarındaki sayısal değişim}

Yayın konusunda 2016 yılı tüm zamanların en üretken yılı olarak belirtilebilir. Yıllar içerisinde genel olarak makale sayılarında yükselen bir eğilim söz konusudur. Bu yayın portföyünün oluşmasına en çok katkı veren başlıca yazarlar Tablo 1'de sunulmuştur.

Tablo 1. Literatüre 5 ve üzerinde katkıda bulunan yazarlar

\begin{tabular}{llllrr}
\hline Sıra & Yazar & Ülke & Üniversitesi & Makale SayıSI & \% 1379 \\
\hline 1 & Gelaye B & Amerika Birleşik Devletleri (ABD) & Harvard Üniversitesi & 7 & 0,50 \\
2 & Hou AYC & Tayvan & Fu Jen Katholik Üniversitesi & 7 & 0,50 \\
3 & Williams MA & Amerika Birleşik Devletleri (ABD) & Harvard Üniversitesi & 7 & 0,50 \\
4 & Unsal A & Türkive & Osmangazi Üniversitesi & 6 & 0,43 \\
5 & Lowe D & İngiltere & Aintree Üniversitesi & 5 & 0,36 \\
6 & Rogers SN & İngiltere & Aintree Üniversitesi & 5 & 0,36 \\
7 & Sarrico CS & Portekiz & Lizbon Üniversitesi & 5 & 0,36 \\
\hline
\end{tabular}

1379 çalışma referans verilen yazarlara göre (ilk yazarlara göre) 27147 yazar analiz edilmiştir. 1379 çalışmada 20 ve üzerinde referans verilen yazar sayısı 100 'dür. Ortak atıf analizi ile bu eserler incelendiğinde en fazla atıf alan ilk 10 yazar sırasıyla; Harvey $L$ (f:217), Parasuraman A (f:137), Marsh HW (f:87), Stensaker B (f:76), Buysse DJ (f:62), Ramsden P (f:61), Astin AW (f:56), Marginson $S$ (f:52), Dill DD (f:50) ve Brennan J (f:50) şeklindedir.

Aşağıda yazarların yıllara göre yayınladıkları araştırma makaleleri ile yazarlar arasındaki ilişki yıllar içindeki değişim atıf analizine göre sunulmaktadır (Şekil 2). ilgili şekil 2674 yazar için minimum 1 atıf kriterine göre bu alanda en fazla atıf alan ilk üç yazar sırasıyla yayınladığı bir araştırma makalesi ile Ramsden P (atıf:442), yayınladığı üç araştırma makalesi ile Smith JA (atıf:324), beş araştırma makalesi ile Lowe D (atıf:322) ve Rogers SN (atıf:322) şeklindedir.

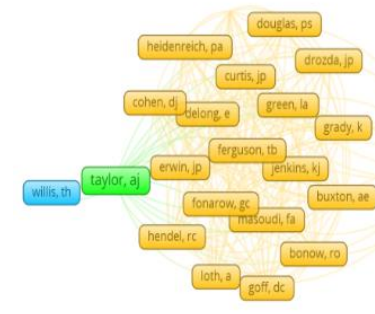

A vosviewer

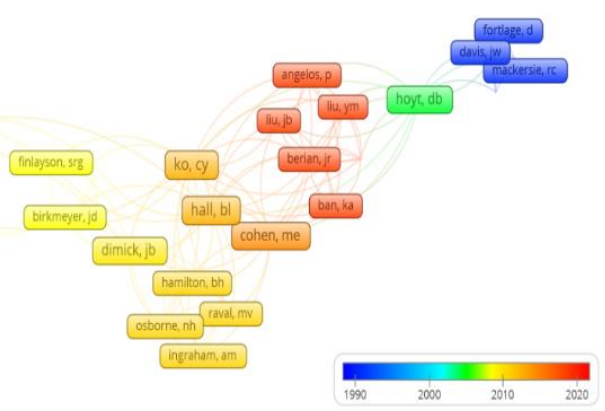

Şekil 2. Ortak yazarlık analizine göre yıllara göre yazarların makale sayıları arasındaki ilişki 
Ülkeler boyutunda literatür incelendiğinde, Tablo 2'deki dağılım ile karşılaşılmaktadır. Bu alanda literatüre en fazla katkı veren ülke ABD olup, arkasından İngiltere ve Avustralya gelmekte ve onları Çin Halk Cumhuriyeti izlemektedir. Yayın dağılımının üniversiteler bazındaki durumu Tablo 3'te sunulmaktadır. Türkiye yayın sayısı konusunda yedinci sırada yer almaktadır ve ortalama atıf sayısı ya da ülke bazında Atıf Alma Durumu 9,28 olup, küresel ölçekte gerçekleştirilen çalışmaların \%2,90’lık kısmını gerçekleştirmiştir. Türkiye yükseköğretim ve kalite konulu çalışmalar hususunda son yıllarda WoS tarafından taranan dergilerde yıllık 3-5 çalışma arasında yayına sahiptir.

Tablo 2. Literatüre en yoğun katkı sağlayan ilk 20 ülke

\begin{tabular}{|c|c|c|c|c|c|c|c|c|c|c|c|}
\hline Sira & Ülkeler & $\begin{array}{c}\text { Makale } \\
\text { Sayısı }\end{array}$ & $\begin{array}{c}\text { Atıf } \\
\text { Sayısı }\end{array}$ & $\begin{array}{c}\text { Ortalama Atıf } \\
\text { Sayısı }\end{array}$ & $\% 1379$ & Sira & Ülkeler & $\begin{array}{c}\text { Makale } \\
\text { Sayısı }\end{array}$ & $\begin{array}{c}\text { Atıf } \\
\text { Sayısı }\end{array}$ & $\begin{array}{c}\text { Ortalama Atıf } \\
\text { Sayısı }\end{array}$ & $\begin{array}{c}\% \\
1379 \\
\end{array}$ \\
\hline 1 & $A B D$ & 426 & 6580 & 15,45 & 30,89 & 11 & Brezilya & 31 & 178 & 5,74 & 2,24 \\
\hline 2 & İngiltere & 122 & 1963 & 16,09 & 8,84 & 12 & Almanya & 31 & 281 & 9,06 & 2,24 \\
\hline 3 & Avustralya & 94 & 1380 & 14,68 & 6,81 & 13 & Güney Afrika & 29 & 105 & 3,62 & 2,10 \\
\hline 4 & Çin & 83 & 409 & 4,93 & 6,01 & 14 & Hollanda & 27 & 292 & 10,81 & 1,95 \\
\hline 5 & İspanya & 56 & 453 & 8,09 & 4,06 & 15 & Hindistan & 23 & 46 & 2,00 & 1,66 \\
\hline 6 & Kanada & 51 & 394 & 7,73 & 3,69 & 16 & Portekiz & 22 & 107 & 4,86 & 1,59 \\
\hline 7 & Türkiye & 40 & 371 & 9,28 & 2,90 & 17 & Malezya & 20 & 66 & 3,30 & 1,45 \\
\hline 8 & İran & 37 & 52 & 1,41 & 2,68 & 18 & Romanya & 19 & 72 & 3,79 & 1,37 \\
\hline 9 & İtalya & 37 & 301 & 8,14 & 2,68 & 19 & Suudi Arabistan & 19 & 72 & 3,79 & 1,37 \\
\hline 10 & Tayvan & 35 & 250 & 7,14 & 2,53 & 20 & İsveç & 19 & 147 & 7,74 & 1,37 \\
\hline
\end{tabular}

Aşağıda tablo incelendiğinde yükseköğretim ve kalite konulu araştırmalar hususunda ilk beş üniversite Michigan Üniversitesi, Harvard Üniversitesi, Pensilvanya Eyalet Üniversitesi, Arizona Üniversitesi, Islamic Azad Üniversitesi şeklinde sıralanmaktadır (Tablo 3).

Tablo 3. Literatüre 10 ve üzeri sayıda katkıda bulunan üniversite veya diğer kurumlar

\begin{tabular}{|c|c|c|c|c|c|c|}
\hline Sira & Üniversite veya Diğer Kurumlar & Ülke & Makale Sayısı & Atıf Sayısı & Ortalama Atıf Sayısı & $\% 1379$ \\
\hline 1 & Michigan Üniversitesi & $A B D$ & 18 & 549 & 30,50 & 1,30 \\
\hline 2 & Harvard Üniversitesi & $A B D$ & 13 & 452 & 34,77 & 0,94 \\
\hline 3 & Pensilvanya Eyalet Üniversitesi & $A B D$ & 13 & 257 & 19,77 & 0,94 \\
\hline 4 & Arizona Üniversitesi & $A B D$ & 12 & 210 & 17,50 & 0,87 \\
\hline 5 & Islamic Azad Üniversitesi & İran & 11 & 5 & 0,45 & 0,79 \\
\hline 6 & Washington Üniversitesi & $A B D$ & 11 & 651 & 59,18 & 0,79 \\
\hline 7 & Kaliforniya Üniversitesi, Los Angeles & $A B D$ & 10 & 356 & 35,60 & 0,72 \\
\hline 8 & Illinois Üniversitesi & $A B D$ & 10 & 67 & 6,70 & 0,72 \\
\hline 9 & Wisconsin Üniversitesi & $\mathrm{ABD}$ & 10 & 89 & 8,90 & 0,72 \\
\hline
\end{tabular}

Yükseköğretim ve kalite konulu çalışmalarda en sık kullanılan kelimelerin yoğunluğu Şekil 3 üzerinde ifade edilmektedir. Yükseköğretim (f:221), kalite güvence (f:99), performans (f:91), öğrenciler (f:75), kalite (f:70), model (f:64), eğitim ( $f: 62)$, sağlık (f:58), yönetim (f:57), yaşam kalitesi (f:56), akreditasyon (f:50), üniversite (f:49), ergenlik (f:48), kolej öğrencileri (f:46), hizmet kalitesi (f:44), memnuniyet (f:42), algılama (f:38), depresyon (f:36) gibi kelimeler aşağıda şekil üzerinde gösterildiği gibi ön plana çıkmaktadır.

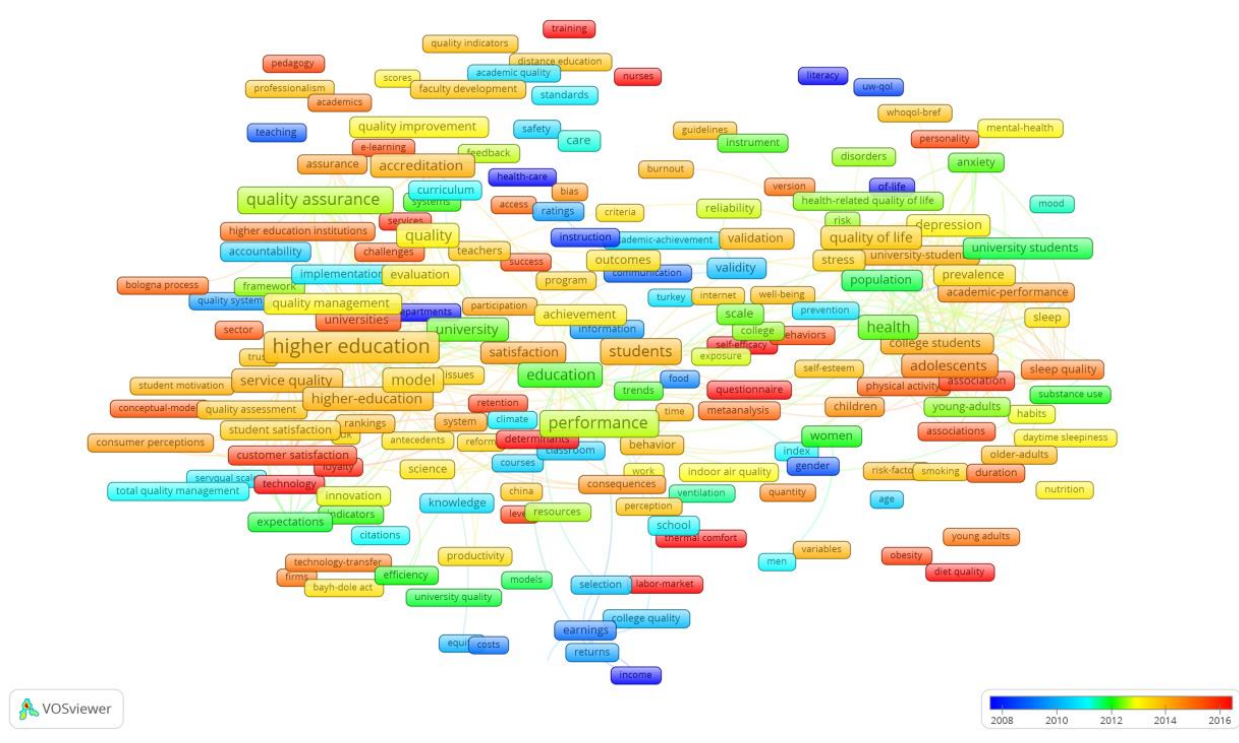

Şekil 3. Araştırma makalelerinde kullanılan anahtar kelime yoğunluğu

Türkiye adresli çalışmalarda kullanılan anahtar kelimeler bakımından incelendiğinde, yükseköğretim (f:7), ergen (f:6), Türkiye (f:6), yaşam kalitesi (f:5), model (f:4), öğrenciler (f:4), depresyon (f:3), yaygınlık (f:3), belirtiler (f:3), okul (f:3), performans (f:3), risk (f:3), öğrenme kalitesi (f:3) ve kalite yönetimi (f:3) çalışmalarda yoğun kullanılan kelimelerdir. 
Araştırma kapsamına alınan makalelerin tanımlandığı alanlara göre dağıımı Tablo 4'te özetlenmektedir. Doğal olarak, Eğitim ve Eğitim Araştırmaları alanı en yüksek frekansa sahiptir. Ancak, diğer alanlarda bu kapsamda yapılan araştırmalar da azımsanamaz. Özellikle sosyal bilimler ve alt alanlarında da bu çalışmaların yoğun olarak yürütüldüğü görülmektedir. Türkiye adresli çalışmaların (40 çalışma); Eğitim ve Eğitimi Araştırmaları (f:10, 25\%), Genel İç Hastalıkları (f:6, 15\%), İşletme Ekonomisi (f:5, $12,50 \%)$, Çevre Bilimleri ve Ekoloji (f:4, 10\%) ve Psikoloji (f:3, 7,50 \%) alanlarında yoğunlaştığı görülmektedir.

Tablo 4. Araştırma makalelerinin araştırma alanlarına göre yoğunlaştığı ilk 20 alan

\begin{tabular}{|c|c|c|c|c|c|c|c|}
\hline Sira & Araştırma Alanı & Makale Sayısı & $\% 1379$ & Sira & Araştırma Alanı & Makale Sayısı & $\% 1379$ \\
\hline 1 & Eğitim ve Eğitimi Araştırmaları & 515 & 37,34 & 11 & Çevre Bilimleri ve Ekoloji & 32 & 2,32 \\
\hline 2 & İşletme Ekonomisi & 215 & 15,59 & 12 & Kamu Yönetimi & 27 & 1,95 \\
\hline 3 & Psikoloji & 95 & 6,88 & 13 & Hemşirelik & 26 & 1,88 \\
\hline 4 & Mühendislik & 63 & 4,56 & 14 & Psikiyatri & 25 & 1,81 \\
\hline 5 & Kamu Çevre İş Sağlığı ve Güvenliği & 61 & 4,42 & 15 & Sinir Bilimleri ve Nöroloji & 24 & 1,74 \\
\hline 6 & Bilgi Bilimi Kütüphane Bilimi & 59 & 4,27 & 16 & Sosyoloji & 24 & 1,74 \\
\hline 7 & Sosyal Bilimler ve Diğer Konular & 59 & 4,27 & 17 & Bilim Teknolojisi Diğer Konular & 23 & 1,66 \\
\hline 8 & Sağlık Bakım Bilimleri ve Hizmetleri & 48 & 3,48 & 18 & Devlet Hukuku & 21 & 1,52 \\
\hline 9 & Bilgisayar Bilimi & 42 & 3,04 & 19 & Gıda Bilim Teknolojisi & 20 & 1,45 \\
\hline 10 & Genel İç Hastalıkları & 38 & 2,75 & 20 & Matematik & 20 & 1,45 \\
\hline
\end{tabular}

Yayınlandıkları dergilere göre dağılım incelendiğinde Tablo 5'deki gibi bir yapı ortaya çıkmaktadır. Pek çok çalışmanın eğitim kapsamındaki dergilerde yapıldığı, en çok yayın yapan dergilerin "Higher Education" ve "Quality In Higher Education" olduğu görülmektedir. Diğer alanların önde gelen dergilerinde de eğitim ve kalite kapsamında çalışmalar yer bulmaktadır. 1379 çalışmanın kaynakçası analiz edildiğinde 18689 farklı kaynağa referans verilmiştir. Minimum 268 kaynak 20 ve üzerinde ilgili çalışmalarda referans gösterilmiştir. Bu eserler arasında en yoğun referans verilen ilk 10 dergi; Higher Education (f:494), Quality Assurance Education (f:282), Quality Assurance in Education (f:257), Research Policy (f:249), Assessment \& Evaluation in Higher Education ( $f: 240)$, Quality in Higher Education ( $f: 227)$, Research in Higher Education (f:221), Economics of Education Review ( $f: 220)$, Total Quality Management (f:209), Studies in Higher Education (f:209), şeklindedir.

\section{Tablo 5. Makalelerin en yoğun yayınlandığı ilk 20 dergi}

\begin{tabular}{|c|c|c|c|c|c|c|}
\hline Sira & Dergi & $\begin{array}{c}\text { Son } 5 \text { yıl } \\
\text { Etki Değeri }\end{array}$ & $\begin{array}{l}\text { Yayınlayan } \\
\text { Ülke }\end{array}$ & Araştırma Alanı & $\begin{array}{c}\text { Makale } \\
\text { Sayısı }\end{array}$ & $\% 1379$ \\
\hline 1 & Higher Education & 2,659 & Hollanda & Education \& Educational Research & 60 & 4,35 \\
\hline 2 & Quality in Higher Education & - & İngiltere & Education \& Educational Research & 32 & 2,32 \\
\hline 3 & Total Quality Management & - & İngiltere & Business \& Economics & 26 & 1,88 \\
\hline 4 & Studies in Higher Education & 2,996 & İngiltere & Business \& Economics & 19 & 1,37 \\
\hline 5 & $\begin{array}{l}\text { Total Quality Management Business } \\
\text { Excellence }\end{array}$ & 1,971 & İngiltere & Business \& Economics & 17 & 1,23 \\
\hline 6 & Quality Assurance in Education & - & İngiltere & Business \& Economics & 15 & 1,08 \\
\hline 7 & Social Indicators Research & 2,027 & Hollanda & Social Sciences - Other Topics; Sociology & 15 & 1,08 \\
\hline 8 & Journal of Higher Education & 2,762 & İngiltere & Education \& Educational Research & 14 & 1,01 \\
\hline 9 & Agro Food Industry Hi Tech & 0,322 & İtalya & $\begin{array}{l}\text { Biotechnology \& Applied Microbiology; Food } \\
\text { Science \& Technology }\end{array}$ & 13 & 0,94 \\
\hline 10 & Economics of Education Review & 1,981 & İngiltere & $\begin{array}{l}\text { Business \& Economics; Education \& Educational } \\
\text { Research }\end{array}$ & 13 & 0,94 \\
\hline 11 & Research in Higher Education & 2,876 & $A B D$ & Education \& Educational Research & 13 & 0,94 \\
\hline 12 & Assessment Evaluation in Higher Education & 2,358 & İngiltere & Education \& Educational Research & 12 & 0,87 \\
\hline 13 & Scientometrics & 2,389 & Hollanda & $\begin{array}{l}\text { Computer Science; Information Science \& Library } \\
\text { Science }\end{array}$ & 11 & 0,79 \\
\hline 14 & Academic Medicine & 5,1 & $A B D$ & $\begin{array}{l}\text { Education \& Educational Research; Health Care } \\
\text { Sciences \& Services }\end{array}$ & 9 & 0,65 \\
\hline 15 & Higher Education Policy & 1,269 & İngiltere & Education \& Educational Research & 9 & 0,65 \\
\hline 16 & Journal of American College Health & 2,313 & İngiltere & $\begin{array}{l}\text { Education \& Educational Research; Public, } \\
\text { Environmental \& Occupational Health }\end{array}$ & 9 & 0,65 \\
\hline 17 & Policy and Society & 1,922 & İngiltere & Government \& Law; Public Administration & 9 & 0,65 \\
\hline 18 & Quality Quantity & 1,154 & Hollanda & Social Sciences - Other Topics; Mathematics & 9 & 0,65 \\
\hline 19 & Accreditation and Quality Assurance & 0,639 & $A B D$ & Chemistry; Instruments \& Instrumentation & 8 & 0,58 \\
\hline 20 & Australian Journal of Education & 1,185 & Avustralya & Education \& Educational Research & 8 & 0,58 \\
\hline
\end{tabular}

Türkiye adresli gerçekleştirilen çalışmalarınsa çoğunlukla; Eğitim ve Bilim Education and Science (f:6, 15,00\%, son beş yıl etki değeri: 0,455, araştırma alanı: Eğitim ve Eğitim Araştırmaları); Social Indicators Research (f:2, 5\%, son beş yıl etki değeri: 2,027, araştırma alanı: Sosyal Konular ve Diğer Başlıklar ile Sosyoloji); Turkish Online Journal of Educational Technology (f:2, 5\%, son beş yıl etki değeri: bulunmuyor, araştırma alanı: Eğitim ve Eğitim Araştırmaları); Upsala Journal of Medical Sciences (f:2, 5\%, son beş yıl etki değeri: 2,355, araştırma alanı: Genel İç Hastalıkları) gibi dergilerde yayınlandığı görülmektedir.

Türkiye adresli 40 çalışmada 889 farklı kaynağa referans verilmiştir. 40 eserde 10 ve üzerinde referans gösterilen çalışmalar analiz edildiğinde, bu alanda en yoğun referans verilen ilk 10 kaynak sırasıyla; Social Indicators Research (f:29), Environment and Behavior (f:21), Landscape and Urban Planning (f:19), Atmospheric Environment (f:19), tezler (f:15), Chronobiology International 
(f:15), Personality and Individual Differences (f:12), Quality Assurance in Education (f:12), Total Quality Management (f:12), Building and Environment ( $\mathrm{f}: 11$ ) şeklinde sıralanmaktadır.

Bu bölümde verilen analiz sonuçları, tartışma ve sonuç bölümünde genel bir perspektiften değerlendirilerek, öne çıkan konu ve unsurlar literatürdeki örnekleri ile birlikte tartışılmaktadır.

\section{Tartışma, Sonuç ve Öneriler}

Çalışmada 80 'lerden günümüze yükseköğretimde kalite çalışmalarının küresel ölçekte değerlendirilmesi hedeflenmiş ve bu ölçekte bulgular paylaşılmıştır. 1980-2018 yılları arasında, başlığında yükseköğretim ve kalite konusunu içeren çalışmalar bilimetrik yöntemler ile incelenmiştir. Analizlere dahil edilen veri setinde, toplam 1379 makale, 3604 yazar, 1434 üniversite, 95 ülke bulunmaktadır. Bilimetrik yöntem ve araçların desteğiyle, kapsama alınan makalelerin en fazla referans verdikleri dergiler, en fazla referans verilen yazarlar ve en fazla yayın üreten ülkeler, özet tablolarla; yazarların ve anahtar kelimelerin kendi arasındaki ilişkiler ise metin analitiği ve ağ analizleri sonucu elde edilen haritalarla sunulmuştur.

Çalışmalar incelediğinde, yapılan araştırmaların sadece üniversite, fakülte ve meslek yüksekokullarındaki kalite sistemi çalışmaları olmadığı görülmüştür. Bu çalışmalara ek olarak, kütüphanelerin gelişimi ve standartlar (Coleman, Jarred, 1994; Ifidon, 1995), laboratuvar akreditasyonu (Bode, 1995) ve iyileştirme programları (Nielsen, 1997), staj konuları (Sarwerfoner, 1981), üniversite web sitesi kalitesi (Thelwall, 2002) gibi konuların da yükseköğretimde kaliteyi etkileyen konular olarak, bu başıkla örtüştürüldüğü ortaya çıkmıştır. Öğrenci ve çalışanların yaşam kalitesi ve iş doyumu (Tolor, 1983; Daskapan, Tuzun ve Eker, 2005; Damush, Hays ve DiMatteo, 1997), fiziksel alanın eğitime etkisi (Mateo, Fernandez, 1996) yükseköğretimde kalite başlığı altında yoğun çalışılan konular arasında yer almaktadır. Çalışmalarda sadece öğrencilerin yaşam kalitesi değil, üniversitede sunulan hizmetlerin kalitesi (Johnsrud, 2002) ve üniversite-toplum işbirliği (Bass, 1987) de literatürde tartışılan konular arasındadır.

Literatürde, yükseköğretimde toplam kalite ile ilgili çalışmaların 90'lar sonrasında ciddi şekilde arttığı görülmüştür (Hansen, 1993; Cowles ve Gilbreath, 1993; Coate, 1993). Kavram, yıllar içinde, toplam kalite yönetiminden kaizen yaklaşımına kadar genişleyen bir çerçevede işlenmiştir (Clayton, 1995). Türk üniversiteleri için toplam kalite kavramının Çoruh (1996)'nın çalışması ile ilk defa 1996 yılında değerlendirildiği görülmüştür. 2000'li yıllara gelindiğinde, küreselleşmenin de etkisi ile sınırları olmayan yükseköğretim ve kalite kavramı literatürde tartışılan önemli konular haline gelmiştir (Farrington, 2001). Bu durum, uluslararasılaşma-küreselleşme kavramı ile kalite kaygısının örtüştüğünün (Van Damme, 2001), küresel pazarın bu yönde gereksiniminin olduğunun ve dolayısıyla tetikleyici bir faktör olduğunun (Yonezawa, 2002; Vidovich, 2002) göstergesi olarak düşünülebilir. 2004-2005 sonrasında uzaktan eğitim ve kalite (Clarke, Butler, Schmidt-Hansen ve Somerville, 2004) yoğun çalışılan bir konu olarak değerlendirilebilir. 2010 ve sonrasında ise problem tabanlı öğrenme (Rakhudu, 2015); üniversite endüstri işbirliği (Kauppila, Mursula, Harkonen, Kujala, 2015); özel ve devlet üniversitelerinde kalite tartışılan önemli konu başlıkları olarak da karşımıza çıkmaktadır (McCowan, 2004). Tüm bunlara ek olarak yükseköğretimde kalite yanında eşitlik kavramı da yoğun işlenen konu başlıkları arasında yer almaktadır (Schwartzman, 2004).

Yazar ve dergi istatistiklerinden elde dilen sonuçlar çerçevesinde, bu alanda çalışan araştırmacıların özellikle, Higher Education ( $f: 60,4,35 \%$ ), Quality In Higher Education ( $f: 32,2,32 \%)$, Total Quality Management ( $f: 26,1,88 \%$ ) dergilerini takip etmeleri de ilgili konudaki yayın sayıları dikkate alınarak önerilebilir. Bunun yanında bu alana katkı sunan ve alana önemli katkılar sunan araştırmacıları (Gelaye B, Hou AYC, Williams MA, Unsal A, Lowe D, Rogers SN, Sarrico CS) özellikle takip etmeleri; önerilebilir.

Türkiye'den araştırmacıların gerçekleştirdiği çalışmaların kaynakları, atıf ağları ve özet istatistiklerle incelendiğinde, en fazla atıf verilen kaynakların çevre, mimari ve davranış konusundaki yayınlar olduğu çalışmanın bulgularına yansıyan bir durumdur. İlgili alanda Türkiye, ülke ve yayın sayısı açısından 40 çalışma ve 371 atıf ile Kanada'nın arkasından yedinci sırada gelmektedir. Bu alanda gerçekleştirilen 40 makale, Türkiye gibi pek çok üniversitenin bulunduğu, yeni bölüm ve programların açıldığı ve genç dinamik bir nüfusa sahip bir ülke için yetersiz bir sayı olarak ifade edilebilir. Bu alanda yapılan araştırmaların teşvik edilmesi adına proje çağrıları oluşturulması ve yükseköğretimde kalite ile ilişkili kongre sempozyum ve konferansların daha çok desteklenmesi önerilebilir.

Sonuç olarak, bu çalışmada, geniş bir literatür özeti ile yükseköğretimde kalite konusu ele alınmış; Web of Science veri tabanlarında yayınlanmış araştırma makalelerinin bilimetrik yapısı gerek özet istatistiklerle ve metriklerle gerekse grafik ve ağ görselleriyle sunularak, öncelikle küresel ölçekte literatürün mevcut durumu ilgili çalışmalarla desteklenerek açıklanmış ve sonrasında da Türkiye adresli yayınların aynı çerçevedeki konumu ortaya konmuştur. Çalışmanın sonuçlarının, bu alanda çalışan ya da çalışacak olan araştırmacılara bir rehber belge niteliği de taşıyacağı ve gelecek çalışmalara ışık tutacağı düşünülmektedir.

\section{Kaynakça}

Adams, J. (2009). The use of bibliometrics to measure research quality in UK higher education institutions. Archivum immunologiae et therapiae experimentalis, 57(1), 19.

Adamu, A. Y., ve Addamu, A. M. (2012). Quality assurance in Ethiopian higher education: Procedures and practices. Procedia Social and Behavioral Sciences, 69, 838 - 846. doi: 10.1016/j.sbspro.2012.12.006.

Adina-Petruta, P., ve Roxana, S. (2014). Integrating six sigma with quality management systems for the development and continuous improvement of higher education Institutions. Procedia - Social and Behavioral Sciences, 143, 643-648. doi: 10.1016/j.sbspro.2014.07.456. 
Al, U. (2008). Bilimsel yayınların değerlendirilmesi: h-endeksi ve Türkiye'nin performansı. Bilgi Dünyası, 9(2), $263-285$.

Alzafari, K. (2017). Mapping the literature structure of 'quality in higher education'using co-word analysis. Quality in HigHer education, 23(3), 264-282.

Barbulescu, A. (2015). Quality culture in the Romanian higher education. Procedia - Social and Behavioral Sciences, 191, 19231927. doi: 10.1016/j.sbspro.2015.04.445.

Bass, S. A. (1987). University and community partnerships: Developing linkages for quality gerontological training and institutional expansion. Educational Gerontology: An International Quarterly, 13(4), 307-324.

Belenli i̇., Günay D., Öztemel E., Demir A., Şerifoğlu F.S.., Elmas M., Eryiğit R., Aydın O., ve Kılıç, M. (2011). Türkiye yükseköğretim kurumları için kalite güvence oluşumu üzerine bir model önerisi. Yükseköğretim ve Bilim Dergisi, 1(3), Aralık/December: 128133.

Bode, P. (1995). Perspective. Quality management and laboratory accreditation at a university: what can be learned from experience? Analyst, 120(5), 1527-1533.

Bogdan, I., luliana, I., Valentin, D., ve Vasile, G. (2009). The quality management of the services of scientometric quantification of the research of the members of the university community deployed within the" e-univroscient" concept. Amfiteatru Economic, 11(26), 429-440.

Brown, R.D. ve Nunn, E.K.(1981). The Quality of Research in Australian Universities. Search, 12(12), 431-433.

Burgess, H. A. (1989). Achieving quality education: Use of the external examiner system in African Universities. Journal of NurseMidwifery, 34(3), 144-145.,

Clarke, M., Butler, C., Schmidt-Hansen, P. ve Somerville, M. (2004). Quality assurance for distance learning: A case study at Brunel University. British Journal of Educational Technology, 35(1), 5-11.

Clayton, M. (1995). Encouraging the kaizen approach to quality in a university. Total Quality Management, 6(5), $593-602$.

Coate, E. (1993). The introduction of total quality management at Oregon State University. Higher Education, 25(3), 303-320.

Coleman, P., ve Jarred, A. D. (1994). Regional association criteria and the Standards for College Libraries: the informal role of quantitative input measures for libraries in accreditation. The Journal of Academic Librarianship, 20(5-6), 273-284.

Cowles, D., ve Gilbreath, G. (1993). Total quality management at Virginia Commonwealth University: an urban university struggles with the realities of TQM. Higher Education, 25(3), 281-302.

Çoruh, M. (1996). Implementation of Total Quality Management at Başkent University. International Journal for Quality in Health Care, 8(1), 83-84.

Damush, T. M., Hays, R. D., ve DiMatteo, M. R. (1997). Guality of Life in College Students. Journal of College Student Development, 38, 2.

Daskapan, A., Tuzun, E. H., ve Eker, L. (2005). Relationship between physical activity level and health related quality of life among university students. Saudi Medical Journal, 26(6), 1026.

Doğramacı i. (2007). Türkiye'de ve dünyada yükseköğretim yönetimi. METEKSAN A.Ş. Ankara. Erişim adresi: http://www.bilkent.edu.tr/hocabey/turkiyede_ve_dunyada_yuksek_ogretim_yonetimi.pdf

Dragan, M., Ivana, D., ve Arba, R. (2014). Business process modeling in higher education institutions. developing a framework for total quality management at institutional level. Procedia Economics and Finance, 16, 95 - 103. doi: 10.1016/S22125671(14)00779-5.

Draguta, B. M. (2011). Quality management in higher education services. Procedia Social and Behavioral Sciences, 15, 3366-3368. doi:10.1016/j.sbspro.2011.04.301.

Ergul, S. Ardahan, M. Temel, A.B. ve Yıldırım, B.Ö. (2010). Bibliometric review of references of nursing research papers during the decade 1994-2003 in Turkey, International Nursing Review. International Council of Nurses. 49-55.

Eryılmaz, M. E., Kara, E., Aydoğan, E., Bektaş, O., ve Erdur, D. A. (2016). Quality management in the Turkish higher education institutions: preliminary findings. Procedia Social and Behavioral Sciences, 229, 60-69. doi: 10.1016/j.sbspro.2016.07.114.

Farrington, D. J. (2001). Borderless higher education: challenges to regulation, accreditation and intellectual property rights. Minerva, 39(1), 63-84.

Garfield, E. (2009). From the science of science to Scientometrics visualizing the history of science with HistCite software. Journal of Informetrics, 3(3), 173-179. doi:10.1016/j.joi.2009.03.009. 
Gencel, U. (2001). Yükseköğretim hizmetlerinde toplam kalite yönetimi ve akreditasyon. Dokuz Eylül Üniversitesi Sosyal Bilimler Enstitüsü Dergisi, 3(3), 164-218.

Gorea, B., ve Saharov, N. (2015). Legislative bases for quality assurance in Romanian higher education. Procedia - Social and Behavioral Sciences, 177, 387 - 391. doi: 10.1016/j.sbspro.2015.02.372.

Günay, D., ve Günay, A. (2017). Historical development and current situation of higher education in Turkey. Yükseköğretim Dergisi, 7 (3), 156-178. doi:10.2399/yod.17.024.

Gür B.S. ve Özer, M. (2012). Türkiye'de yükseköğretimin yeniden yapılandırılması ve kalite güvence sistemi. siyaset ekonomi ve toplum araştırmaları (SETA) çalıştayı. Pelin Ofset, Ankara. Erişim adresi: http://file.setav.org/Files/Pdf/20121217125617_zonguldak-web2.pdf

Hansen, W. L. (1993). Bringing total quality improvement into the college classroom. Higher Education, 25(3), 259-279.

Harvey, L. ve Green, D. (1993). Defining quality. Assessment and Evaluation in Higher Education, 18(1), 9-34.

Hosseini, M. R., Martek, I., Zavadskas, E. K., Aibinu, A. A., Arashpour, M., ve Chileshe, N. (2018). Critical evaluation of off-site construction research: A Scientometric analysis. Automation in Construction, 87, 235-247. doi: 10.1016/j.autcon.2017.12.002.

Ifidon, B. I. (1995). Recent Developments in Nigerian Academic Libraries: The Effects of Accreditation on University Lybrary Bookstock. Libri, 45(3-4), 186-198.

Johnsrud, L. K. (2002). Measuring the quality of faculty and administrative worklife: Implications for college and university campuses. Research in Higher Education, 43(3), 379-395.

Kanji, G.K., Tambi, A.M.A. (1998). Total quality management and higher education in Malaysia. Total Quality Management, 9:4-5, 130-132, doi: 10.1080/0954412988749.

Karahan, M., ve Mete, M. (2014). Examination of total quality management practices in higher education in the context of quality sufficiency. Procedia - Social and Behavioral Sciences, 109, 1292 - 1297. doi: 10.1016/j.sbspro.2013.12.627.

Kauppila, O., Mursula, A., Harkonen, J., ve Kujala, J. (2015). Evaluating university-industry collaboration: the European Foundation of Quality Management excellence model-based evaluation of university-industry collaboration. Tertiary Education and Management, 21(3), 229-244.

Keçetep, I.., ve Özkan, I. (2014). Quality assurance in the European higher education area. Procedia - Social and Behavioral Sciences, 141, 660 - 664. doi: 10.1016/j.sbspro.2014.05.115.

Mateo, M. A. ve Fernandez, J. (1996). Incidence of class size on the evaluation of university teaching quality. Educational and Psychological Measurement, 56(5), 771-778.

McCowan, T. (2004). The growth of private higher education in Brazil: implications for equity and quality. Journal of Education Policy, 19(4), 453-472.

Moodie, G. C. (1988). The debates about higher education quality in Britain and the USA. Studies in Higher Education, $13(1), 5-13$.

Nielsen, M. L. (1997). Cytopathology laboratory improvement programs of the college of American pathologists. Archives of Pathology \& Laboratory Medicine, 121(3), 256.

Özdemir, A. N. ve Alpaydın, Y. (2018). Yükseköğretim kurumlarında akademik yayıncılık: Üniversite dergilerinin bazı değişkenler açısından incelenmesi. Yükseköğretim Dergisi, 8(1), 9-22. doi:10.2399/yod.17.026

Pardo, C. Reolid, M. Delicado, M-V. Mallebrera, E. ve Garcia-Meseguer, M-J. (2001). Nursing research in Spain: bibliometrics of references of research papers in the decade 1985-1994. Journal of Advanced Nursing, 35(6), 933-943.

Pereira, C. A., Araujo, J. F. F. E., ve Machado-Taylor, M. d. L. (2018). The Brazilian higher education evaluation model: "SINAES" sui generis? International Journal of Educational Development, 61, 5-15. Doi: 10.1016/j.ijedudev.2017.11.007.

Popescu-Mitroi, M-M., Todorescu, L-L., ve Greculescu, A. (2015). Quality assurance and classroom management in the study of English in technical higher education. Procedia - Social and Behavioral Sciences, 191, 1917 - 1922. doi: 10.1016/j.sbspro.2015.04.724.

Prisacariu, A. (2015). New perspectives of quality assurance in european higher education. Procedia - Social and Behavioral Sciences, 180, 119 - 126. doi: 10.1016/j.sbspro.2015.02.094.

Rakhudu, M. A. (2015). Use of Problem Based Scenarios to Prepare Nursing Students to Address Quality Improvement in Health Care Unit: North West University Experience. International Journal of Educational Sciences, 10(1), 72-80.

Rezeanu, O. M. (2011). The implementation of quality management in higher education. Procedia Social and Behavioral Sciences, 15, 1046-1050. doi:10.1016/j.sbspro.2011.03.237. 
Sarı, A., Fırat, A., ve Karaduman, A. (2016). Quality assurance Issues in higher education sectors of developing countries; case of Northern Cyprus. Procedia - Social and Behavioral Sciences, 229, 326 - 334. doi: 10.1016/j.sbspro.2016.07.143.

Sarwerfoner, G. (1981). The Philosophy Of High-Quality Care By University Hospitals-The Role Modeling Of Residents And The Organization Of High-Quality Services For The Delivery Of Psychiatric Health-Care. Psychiatric Journal of The University of Ottawa-Revue De Psychiatrie De L Universite D Ottawa, 6(1), 4-12.

Schwartzman, S. (2004). Equity, quality and relevance in higher education in Brazil. Anais da Academia Brasileira de Ciencias, 76(1), 173-188.

Shin, J. C. (2017). Quality assurance systems as a higher education policy tool in Korea: International convergence and local contexts. International Journal of Educational Development, doi:10.1016/j.ijedudev.2017.10.005. (baskıda makale).

Tezsürücü, D., ve Bursalıoğlu, S. A. (2013). Yükseköğretimde değişim: kalite arayışları. Kahramanmaraş Sütçü İmam Üniversitesi Sosyal Bilimler Dergisi, 10 (2), 97-108.

Thelwall, M. (2002). The top 100 linked-to pages on UK university web sites: high inlink counts are not usually associated with quality scholarly content. Journal of Information Science, 28(6), 483-491.

Todorescu, L-L., Greculescu, A., ve Lampă, I. (2014). Implementation of quality assurance in Romanian technical higher education - objective set by the Bologna process. Procedia - Social and Behavioral Sciences, 122, 443 - 447. doi: 10.1016/j.sbspro.2014.01.1369.

Todorut, A. V. (2013). The need of total quality management in higher education. Procedia - Social and Behavioral Sciences, 83, 1105 - 1110. doi: 10.1016/j.sbspro.2013.06.207.

Tolor, A. (1983). Perception of quality of life of college students and their faculty. Adolescence, 18(71), 585.

Tonta, Y. (1999). Bilgi toplumu ve bilgi teknolojisi. Türk Kütüphaneciliği, 13(4), 363-375.

Tuijnman, A. (1990). Dilemmas of open admissions policy: quality and efficiency in Swedish higher education. Higher Education, 20(4), 443-457.

Van Damme, D. (2001). Quality issues in the internationalisation of higher education. Higher Education, 41(4), 415-441.

van Eck, N., ve Waltman, L. (2009). Software survey: VOSviewer, a computer program for bibliometric mapping. Scientometrics, 84(2), 523-538. doi: 10.1007/s11192-009-0146-3.

Vidovich, L. (2002). Quality assurance in Australian higher education: Globalisation andsteering at a distance. Higher Education, 43(3), 391-408.

Vinkler, P. (2010). The Evaluation of Research by Scientometric Indicators. Chandos Publishing. Oxford.

Yang, S., ve Yuan, Q. (2017). Are Scientometrics, Informetrics, and Bibliometrics different? 16th International Society of Scientometrics and Informetrics Conference ISSI 2017.

Yonezawa, A. (2002). The quality assurance system and market forces in Japanese higher education. Higher Education, 43(1), 127139.

YÖDEK (2007). Yükseköğretim kurumlarında akademik değerlendirme ve kalite geliştirme rehberi. Yükseköğretim akademik değerlendirme ve kalite geliştirme komisyonu (YÖDEK). Erişim adresi: http://www.yodek.org.tr/yodek/files/7aa12f8d2582deb44d4249c7aa4a2020.pdf

YÖK (2007). Türkiye'nin yükseköğretim stratejisi. Meteksan A.Ş. Ankara. 2007. Erişim adresi: tarihinde https://www.kuzka.gov.tr/dosya/yuksekogretim_stratejisi.pdf 